\title{
Breve análise jurídica acerca da Municipalização do licenciamento ambiental
}

\author{
Brief Legal analysis about the Municipalization of environmental \\ licensing
}

\author{
André Serotini ${ }^{1}$ \\ Isadora de Freitas Luvizoto ${ }^{2}$
}

\section{RESUMO}

A Lei Complementar $n^{\circ}$. 140, de 8 de novembro de 2011, fixou normas relacionadas à competência comum material estabelecida no artigo 23 da Constituição Federal de 1988 (CRFB/88), em especial, para os fins propostos neste artigo, sobre a proteção do meio ambiente e combate de qualquer forma de poluição (inciso VI), regulamentando a cooperação entre União, Estados, Distrito Federal e Municípios nas ações administrativas de caráter ambiental, inclusive sobre o licenciamento. E, sobre este último aspecto, é que se buscam elucidações acerca do papel do município nos licenciamentos ambientais (processo de municipalização do licenciamento ambiental). Para o atingimento do resultado pretendido adota-se a revisão bibliográfica e pesquisa documental, utilizando-se de fontes primárias diretas como o arcabouço normativo nacional relacionado à proteção do meio ambiente e, de forma dedutiva, busca-se apresentar visão qualitativa que possa trazer contribuições para o debate sobre as possíveis vantagens do licenciamento ambiental em nível municipal no Brasil.

\section{PALAVRAS-CHAVES}

Licenciamento ambiental, Competência ambiental, Municipalização.

\begin{abstract}
Complementary Law no. 140, of November 8, 2011, established rules related to the material common competence established in art. 23 of the Federal Constitution of 1988 (CRFB / 88), in particular, for the purposes proposed in this article, on the protection of the environment and the fight against any form of pollution (item VI), regulating the cooperation between the Union, the States, the Federal District. and Municipalities in environmental administrative actions, including licensing. And, on this last aspect, it is sought to elucidate about the role of the municipality in environmental licensing (process of municipalization of environmental

\footnotetext{
${ }^{1}$ Docente do Curso de Direito e do Programa de Mestrado em Ciências Ambientais da Universidade do Estado de Minas Gerais -UEMG - Unidade Frutal e do Curso de Direito do Centro Universitário Central Paulista - UNICEP - São Carlos. Doutor em Ciência Política pela Universidade Federal de São Carlos - PPGPOL/UFSCar, Mestre em Desenvolvimento Regional e Meio Ambiente pela Universidade de Araraquara - UNIARA, Bacharel em Direito pela Faculdade de Direito de São Carlos - FADISC. Pesquisador do Núcleo de Estudos em Gestão e Impactos Ambientais - NEGIA e do Grupo de Pesquisa Uso e Conservação de Recursos Naturais, ambos da UEMG - Frutal. https://orcid.org/0000-0003-4100-6882. Lattes: http://lattes.cnpq.br/1395564531728373.

${ }^{2}$ Bacharela em Direito pela Universidade do Estado de Minas Gerais (UEMG) - Brasil. Bolsista PAPq/UEMG.
} 
licensing). To achieve the desired result, a literature review and documentary research are adopted, using direct primary sources such as the national normative framework related to the protection of the environment and, in a deductive way, we seek to present a qualitative view that can bring contributions. for the debate on the possible advantages of environmental licensing at the municipal level in Brazil.

\section{KEYWORDS}

Environmental licensing, Environmental competence, Municipalization.

\section{INTRODUÇÃO}

Com o advento da Lei Complementar $n^{\circ}$. 140, de 8 de novembro de 2011, fixando normas relacionadas à competência comum material estabelecida no artigo 23 da Constituição Federal de 1988 (CRFB/88), sobre a proteção de documentos, bens de valor histórico, artístico e cultural, paisagens naturais notáveis e sítios arqueológicos (inciso III); proteção do meio ambiente e combate de qualquer forma de poluição (inciso VI); e, preservação das florestas, fauna e flora (inciso VII), a tão necessária cooperação nas ações administrativas entre União, Estados, Distrito Federal e Municípios ganha relevância e passa a ser considerada nos processos de licenciamento ambiental.

A elaboração da referida lei está intimamente relacionada à norma constitucional de eficácia limitada residente no parágrafo único do mesmo artigo 23 mencionado anteriormente, a qual, para sua efetividade dependia, até então, da fixação de normas, por meio de Leis Complementares, disciplinando a cooperação entre os entes federativos, visando o equilíbrio do desenvolvimento e do bem-estar em âmbito nacional.

Em decorrência desta positivação, especialmente em nível local, os Municípios passaram, de acordo com o previsto no artigo $9^{\circ}$, da Lei Complementar $\mathrm{n}^{\circ}$. 140/2011, a contar com a possibilidade de promover o seu próprio procedimento de licenciamento ambiental de atividades ou empreendimentos que causem ou possam causar impacto ambiental de âmbito local ou localizadas em unidades de conservação instituídas pelo próprio município, com exceção das Áreas de Proteção Ambiental. 
Todavia, a aplicação desta possibilidade carece do cumprimento de certos requisitos, como está disposto no artigo 18, da referida Lei, na qual se estabelece que sua aplicação darse-á, apenas aos processos de licenciamento e autorização ambiental iniciados a partir de sua vigência, ou seja, 09 de dezembro de 2011, vinculando-se ainda, a edição da decisão do respectivo Conselho Estadual e, enquanto esta não for proferida, aplicar-se-á a legislação até então em vigor.

Desta forma, com exceção daquelas competências constitucionais locais atribuídas aos municípios, esse somente poderá estabelecer procedimentos de licenciamento ambiental para as atividades e empreendimentos localizados em seu território caso mantenha o cumprimento dos requisitos estabelecidos pelo Conselho Estadual de Meio Ambiente.

Com o escopo de elucidar este processo de municipalização do licenciamento ambiental, aborda-se no decorrer deste artigo, preliminarmente, sobre a organização de competências ambientais de acordo com a Constituição Federal de 1988; na sequência foca-se no licenciamento ambiental como um dos principais instrumentos da Política Nacional do Meio Ambiente, amparada na Lei $n^{\circ}$. 6.938/1981; analisa os requisitos apresentados pela Lei Complementar $n^{\circ}$. 140/2011; e, por fim, busca-se entender quais os possíveis benefícios que o processo de municipalização pode trazer para a efetivação da defesa do meio ambiente.

\section{DISTRIBUIÇÃO DE COMPETÊNCIAS DE ACORDO COM A CONSTITUIÇÃO FEDERAL DE 1988.}

Esclarece-se, ao tratar de competências dos entes federativos, que a Assembleia Constituinte de 1987/88, atribuiu funções administrativas e legislativas à União, Estados, Distrito Federal e Municípios. De acordo com Pablo Lucas Verdú, a repartição de competências é considerada a "chave da estrutura do poder federal, o problema típico do Estado Federal"3, ou seja, está implícita, no sistema federativo, a necessidade de distribuição de competências

\footnotetext{
${ }^{3}$ VERDÚ, Pablo Lucas. Curso de derecho político. v. 2. Madri: Tecnos, 1974.
} 
para os entes dotados de autonomia, de acordo com o artigo 18, da CRFB/ $/ 88^{4}$. Todavia, esta distribuição de competências acaba sendo desproporcional ao centralizar as principais funções no âmbito da União.

A afirmação acima pode ser percebida ao analisar o modelo adotado pelo constituinte ao enumerar as competências da União, nos artigos $21^{5}$ e $22^{6}$, da CRFB/88 e, após este

\footnotetext{
${ }^{4}$ Art. 18. A organização político-administrativa da República Federativa do Brasil compreende a União, os Estados, o Distrito Federal e os Municípios, todos autônomos, nos termos desta Constituição.

5 Art. 21. Compete à União: I - manter relações com Estados estrangeiros e participar de organizações internacionais; II - declarar a guerra e celebrar a paz; III - assegurar a defesa nacional; IV - permitir, nos casos previstos em lei complementar, que forças estrangeiras transitem pelo território nacional ou nele permaneçam temporariamente; V - decretar o estado de sítio, o estado de defesa e a intervenção federal; VI - autorizar e fiscalizar a produção e o comércio de material bélico; VII - emitir moeda; VIII - administrar as reservas cambiais do País e fiscalizar as operações de natureza financeira, especialmente as de crédito, câmbio e capitalização, bem como as de seguros e de previdência privada; IX - elaborar e executar planos nacionais e regionais de ordenação do território e de desenvolvimento econômico e social; X - manter o serviço postal e o correio aéreo nacional; XI - explorar, diretamente ou mediante autorização, concessão ou permissão, os serviços de telecomunicações, nos termos da lei, que disporá sobre a organização dos serviços, a criação de um órgão regulador e outros aspectos institucionais; XII - explorar, diretamente ou mediante autorização, concessão ou permissão: a) os serviços de radiodifusão sonora, e de sons e imagens; b) os serviços e instalações de energia elétrica e o aproveitamento energético dos cursos de água, em articulação com os Estados onde se situam os potenciais hidroenergéticos; c) a navegação aérea, aeroespacial e a infra-estrutura aeroportuária; d) os serviços de transporte ferroviário e aquaviário entre portos brasileiros e fronteiras nacionais, ou que transponham os limites de Estado ou Território; e) os serviços de transporte rodoviário interestadual e internacional de passageiros; f) os portos marítimos, fluviais e lacustres; XIII - organizar e manter o Poder Judiciário, o Ministério Público do Distrito Federal e dos Territórios e a Defensoria Pública dos Territórios; XIV - organizar e manter a polícia civil, a polícia militar e o corpo de bombeiros militar do Distrito Federal, bem como prestar assistência financeira ao Distrito Federal para a execução de serviços públicos, por meio de fundo próprio; XV - organizar e manter os serviços oficiais de estatística, geografia, geologia e cartografia de âmbito nacional; XVI - exercer a classificação, para efeito indicativo, de diversões públicas e de programas de rádio e televisão; XVII - conceder anistia; XVIII - planejar e promover a defesa permanente contra as calamidades públicas, especialmente as secas e as inundações; XIX - instituir sistema nacional de gerenciamento de recursos hídricos e definir critérios de outorga de direitos de seu uso; XX - instituir diretrizes para o desenvolvimento urbano, inclusive habitação, saneamento básico e transportes urbanos; XXI - estabelecer princípios e diretrizes para o sistema nacional de viação; XXII - executar os serviços de polícia marítima, aeroportuária e de fronteiras; XXIII - explorar os serviços e instalações nucleares de qualquer natureza e exercer monopólio estatal sobre a pesquisa, a lavra, o enriquecimento e reprocessamento, a industrialização e o comércio de minérios nucleares e seus derivados, atendidos os seguintes princípios e condições: a) toda atividade nuclear em território nacional somente será admitida para fins pacíficos e mediante aprovação do Congresso Nacional; b) sob regime de permissão, são autorizadas a comercialização e a utilização de radioisótopos para a pesquisa e usos médicos, agrícolas e industriais; c) sob regime de permissão, são autorizadas a produção, comercialização e utilização de radioisótopos de meia-vida igual ou inferior a duas horas; d) a responsabilidade civil por danos nucleares independe da existência de culpa; XXIV - organizar, manter e executar a inspeção do trabalho; XXV estabelecer as áreas e as condições para o exercício da atividade de garimpagem, em forma associativa

${ }^{6}$ Art. 22. Compete privativamente à União legislar sobre: I - direito civil, comercial, penal, processual, eleitoral, agrário, marítimo, aeronáutico, espacial e do trabalho; II - desapropriação; III - requisições civis e militares, em caso de iminente perigo e em tempo de guerra; IV - águas, energia, informática, telecomunicações e radiodifusão; V - serviço postal; VI - sistema monetário e de medidas, títulos e garantias dos metais; VII - política de crédito, câmbio, seguros e transferência de valores; VIII - comércio exterior e interestadual; IX - diretrizes da política nacional de transportes; X - regime dos portos, navegação lacustre, fluvial, marítima, aérea e aeroespacial; XI trânsito e transporte; XII - jazidas, minas, outros recursos minerais e metalurgia; XIII - nacionalidade, cidadania e naturalização; XIV - populações indígenas; XV - emigração e imigração, entrada, extradição e expulsão de estrangeiros; XVI - organização do sistema nacional de emprego e condições para o exercício de profissões; XVII - organização judiciária, do Ministério Público e da Defensoria Pública do Distrito Federal e dos Territórios, bem
} 
procedimento, de forma remanescente, atribuir as competências estaduais, conforme se deduz da análise do parágrafo $1^{\circ}$, do artigo 25 , da CFRB/88 ${ }^{7}$. Em relação aos Municípios, as suas competências são de abrangência bem reduzidas, tidas como local, como estabelecido no artigo. 30, da CRFB $/ 88^{8}$.

Considera-se, contudo, que estão previstos na Constituição brasileira, outros mecanismos que complementam o sistema de distribuição de competências, possibilitando delegação em matérias específicas reservadas à determinado ente federativo, como é o caso da União, disposto no parágrafo único, do artigo 22, da CRFB/88; competências comuns ou paralelas entre União, Estados, Distrito Federal e Municípios, previstas no artigo 23, da CRFB $/ 88^{9}$; competências concorrentes entre União e Estados, no que diz respeito ao

como organização administrativa destes; XVII - organização judiciária, do Ministério Público do Distrito Federal e dos Territórios e da Defensoria Pública dos Territórios, bem como organização administrativa destes; XVIII sistema estatístico, sistema cartográfico e de geologia nacionais; XIX - sistemas de poupança, captação e garantia da poupança popular; XX - sistemas de consórcios e sorteios; XXI - normas gerais de organização, efetivos, material bélico, garantias, convocação e mobilização das polícias militares e corpos de bombeiros militares; XXII - competência da polícia federal e das polícias rodoviária e ferroviária federais; XXIII - seguridade social; XXIV - diretrizes e bases da educação nacional; XXV - registros públicos; XXVI - atividades nucleares de qualquer natureza; XXVII - normas gerais de licitação e contratação, em todas as modalidades, para a administração pública, direta e indireta, incluídas as fundações instituídas e mantidas pelo Poder Público, nas diversas esferas de governo, e empresas sob seu controle; XXVII - normas gerais de licitação e contratação, em todas as modalidades, para as administrações públicas diretas, autárquicas e fundacionais da União, Estados, Distrito Federal e Municípios, obedecido o disposto no art. 37, XXI, e para as empresas públicas e sociedades de economia mista, nos termos do art. 173, $1^{\circ}$, III; XXVIII - defesa territorial, defesa aeroespacial, defesa marítima, defesa civil e mobilização nacional; XXIX - propaganda comercial. Parágrafo único. Lei complementar poderá autorizar os Estados a legislar sobre questões específicas das matérias relacionadas neste artigo.

${ }^{7}$ Art. 25. Os Estados organizam-se e regem-se pelas Constituições e leis que adotarem, observados os princípios desta Constituição. $\S 1^{\circ}$ São reservadas aos Estados as competências que não lhes sejam vedadas por esta Constituição.

${ }^{8}$ Art. 30. Compete aos Municípios: I - legislar sobre assuntos de interesse local; II - suplementar a legislação federal e a estadual no que couber; III - instituir e arrecadar os tributos de sua competência, bem como aplicar suas rendas, sem prejuízo da obrigatoriedade de prestar contas e publicar balancetes nos prazos fixados em lei; IV criar, organizar e suprimir distritos, observada a legislação estadual; V - organizar e prestar, diretamente ou sob regime de concessão ou permissão, os serviços públicos de interesse local, incluído o de transporte coletivo, que tem caráter essencial; VI - manter, com a cooperação técnica e financeira da União e do Estado, programas de educação infantil e de ensino fundamental; VII - prestar, com a cooperação técnica e financeira da União e do Estado, serviços de atendimento à saúde da população; VIII - promover, no que couber, adequado ordenamento territorial, mediante planejamento e controle do uso, do parcelamento e da ocupação do solo urbano; IX - promover a proteção do patrimônio histórico-cultural local, observada a legislação e a ação fiscalizadora federal e estadual. 9 Art. 23. É competência comum da União, dos Estados, do Distrito Federal e dos Municípios: I - zelar pela guarda da Constituição, das leis e das instituições democráticas e conservar o patrimônio público; II - cuidar da saúde e assistência pública, da proteção e garantia das pessoas portadoras de deficiência; III - proteger os documentos, as obras e outros bens de valor histórico, artístico e cultural, os monumentos, as paisagens naturais notáveis e os sítios arqueológicos; IV - impedir a evasão, a destruição e a descaracterização de obras de arte e de outros bens de valor histórico, artístico ou cultural; V - proporcionar os meios de acesso à cultura, à educação, à ciência, à tecnologia, à pesquisa e à inovação; VI - proteger o meio ambiente e combater a poluição em qualquer de suas formas; VII preservar as florestas, a fauna e a flora; VIII - fomentar a produção agropecuária e organizar o abastecimento alimentar; IX - promover programas de construção de moradias e a melhoria das condições habitacionais e de saneamento básico; X - combater as causas da pobreza e os fatores de marginalização, promovendo a integração 
estabelecimento de políticas, diretrizes e normas gerais, dispostas no $\operatorname{artigo} 24$, da CRFB $/ 88^{10}$; e, competências suplementares, no sentido de possibilitar aos Estados e aos Municípios, a suplementação das competências distribuídas anteriormente, estabelecidas no parágrafo $2^{\circ}$, do artigo anteriormente mencionado.

\subsection{Competências Ambientais}

No que se refere às questões relacionadas ao meio ambiente, constata-se que a Constituição Federal de 1988, além de dispor de norma geral que atribui deveres de proteção ambiental ao Estado, em especial no que compõe o seu artigo $225^{11}$, trouxe um extenso rol

social dos setores desfavorecidos; XI - registrar, acompanhar e fiscalizar as concessões de direitos de pesquisa e exploração de recursos hídricos e minerais em seus territórios; XII - estabelecer e implantar política de educação para a segurança do trânsito. Parágrafo único. Leis complementares fixarão normas para a cooperação entre a União e os Estados, o Distrito Federal e os Municípios, tendo em vista o equilíbrio do desenvolvimento e do bemestar em âmbito nacional.

${ }^{10}$ Art. 24. Compete à União, aos Estados e ao Distrito Federal legislar concorrentemente sobre: I - direito tributário, financeiro, penitenciário, econômico e urbanístico; II - orçamento; III - juntas comerciais; IV - custas dos serviços forenses; V - produção e consumo; VI - florestas, caça, pesca, fauna, conservação da natureza, defesa do solo e dos recursos naturais, proteção do meio ambiente e controle da poluição; VII - proteção ao patrimônio histórico, cultural, artístico, turístico e paisagístico; VIII - responsabilidade por dano ao meio ambiente, ao consumidor, a bens e direitos de valor artístico, estético, histórico, turístico e paisagístico; IX - educação, cultura, ensino e desporto; IX - educação, cultura, ensino, desporto, ciência, tecnologia, pesquisa, desenvolvimento e inovação; X - criação, funcionamento e processo do juizado de pequenas causas; XI - procedimentos em matéria processual; XII - previdência social, proteção e defesa da saúde; XIII - assistência jurídica e Defensoria pública; XIV - proteção e integração social das pessoas portadoras de deficiência; XV - proteção à infância e à juventude; XVI organização, garantias, direitos e deveres das polícias civis. $\S 1^{\circ}$ No âmbito da legislação concorrente, a competência da União limitar-se-á a estabelecer normas gerais. § $2^{\circ}$ A competência da União para legislar sobre normas gerais não exclui a competência suplementar dos Estados. $\S 3^{\circ}$ Inexistindo lei federal sobre normas gerais, os Estados exercerão a competência legislativa plena, para atender a suas peculiaridades. § $4^{\circ} \mathrm{A}$ superveniência de lei federal sobre normas gerais suspende a eficácia da lei estadual, no que lhe for contrário.

${ }^{11}$ Art. 225. Todos têm direito ao meio ambiente ecologicamente equilibrado, bem de uso comum do povo e essencial à sadia qualidade de vida, impondo-se ao Poder Público e à coletividade o dever de defendê-lo e preserválo para as presentes e futuras gerações. $§ 1^{\circ}$ Para assegurar a efetividade desse direito, incumbe ao Poder Público: I - preservar e restaurar os processos ecológicos essenciais e prover o manejo ecológico das espécies e ecossistemas; II - preservar a diversidade e a integridade do patrimônio genético do País e fiscalizar as entidades dedicadas à pesquisa e manipulação de material genético; III - definir, em todas as unidades da Federação, espaços territoriais e seus componentes a serem especialmente protegidos, sendo a alteração e a supressão permitidas somente através de lei, vedada qualquer utilização que comprometa a integridade dos atributos que justifiquem sua proteção; IV - exigir, na forma da lei, para instalação de obra ou atividade potencialmente causadora de significativa degradação do meio ambiente, estudo prévio de impacto ambiental, a que se dará publicidade; V controlar a produção, a comercialização e o emprego de técnicas, métodos e substâncias que comportem risco para a vida, a qualidade de vida e o meio ambiente; VI - promover a educação ambiental em todos os níveis de ensino e a conscientização pública para a preservação do meio ambiente; VII - proteger a fauna e a flora, vedadas, na forma da lei, as práticas que coloquem em risco sua função ecológica, provoquem a extinção de espécies ou submetam os animais a crueldade. $\S 2^{\circ}$ Aquele que explorar recursos minerais fica obrigado a recuperar o meio ambiente degradado, de acordo com solução técnica exigida pelo órgão público competente, na forma da lei. $\S 3^{\circ}$ As condutas e atividades consideradas lesivas ao meio ambiente sujeitarão os infratores, pessoas físicas ou jurídicas, a sanções penais e administrativas, independentemente da obrigação de reparar os danos causados. $\S 4^{\circ}$ 
exemplificativo estipulando atribuições e competências aos entes federativos, visando assegurar efetividade à proteção ecológica. Neste sentido,

\begin{abstract}
O exercício das competências constitucionais (legislativas e executivas) em matéria ambiental, respeitados os espaços político-jurídicos de cada ente federativo, deve rumar para a realização do objetivo constitucional expresso no art. 225 da CRFB/1988, inclusive sob a caracterização de um dever de cooperação entre os entes federativos no cumprimento dos seus deveres de proteção ambiental. Isso implica a adequação das competências constitucionais ambientais ao princípio da subsidiariedade, enquanto princípio constitucional implícito no nosso sistema constitucional, o qual conduz à descentralização do sistema de competências e ao fortalecimento da autonomia dos entes federativos inferiores (ou periféricos) naquilo em que representar fortalecimento dos instrumentos de proteção ambiental e dos mecanismos de participação política, sob o marco jurídico-constitucional de um federalismo cooperativo ecológico ${ }^{22}$.
\end{abstract}

Ressalta-se que, embora cada ente federativo tenha seu conjunto de atribuições, todos devem agir de forma coordenada para a sustentação do Estado e, neste aspecto, fica claro que ao ser alçado à categoria de direito fundamental, o meio ambiente, passa a ser considerado em todo o processo de tomada de decisão política, caracterizando-se desta forma, um federalismo cooperativo ecológico ${ }^{13}$.

\title{
1.2 Competência Legislativa Ambiental
}

Consideram-se, como competências legislativas, aquelas funções legiferantes exercidas pelo Poder Legislativo dos entes federativos com o escopo de se estabelecer um conjunto normativo genérico e vinculante, objetivando a concretização dos objetivos constitucionais do Estado.

\footnotetext{
A Floresta Amazônica brasileira, a Mata Atlântica, a Serra do Mar, o Pantanal Mato-Grossense e a Zona Costeira são patrimônio nacional, e sua utilização far-se-á, na forma da lei, dentro de condições que assegurem a preservação do meio ambiente, inclusive quanto ao uso dos recursos naturais. § $5^{\circ}$ São indisponíveis as terras devolutas ou arrecadadas pelos Estados, por ações discriminatórias, necessárias à proteção dos ecossistemas naturais. $\S 6^{\circ}$ As usinas que operem com reator nuclear deverão ter sua localização definida em lei federal, sem o que não poderão ser instaladas. $\S 7^{\circ}$ Para fins do disposto na parte final do inciso VII do $\S 1^{\circ}$ deste artigo, não se consideram cruéis as práticas desportivas que utilizem animais, desde que sejam manifestações culturais, conforme o $\S 1^{\circ}$ do art. 215 desta Constituição Federal, registradas como bem de natureza imaterial integrante do patrimônio cultural brasileiro, devendo ser regulamentadas por lei específica que assegure o bem-estar dos animais envolvidos. ${ }^{12}$ SARLERT, Ingo Wolfgang; FENSTERSEIFER, Tiago. Direito constitucional ambiental: Constituição, direitos fundamentais e proteção do ambiente. $4^{\mathrm{a}}$ Edição. Revista e atualizada. São Paulo: Revista dos Tribunais, 2014.

${ }^{13}$ SARLERT, Ingo Wolfgang; FENSTERSEIFER, Tiago. Direito constitucional ambiental: Constituição, direitos fundamentais e proteção do ambiente. $4^{a}$ Edição. Revista e atualizada. São Paulo: Revista dos Tribunais, 2014.
} 
Desta forma, a Constituição Federal de 1988 atribuiu competências legislativas privativas à União ${ }^{14} \mathrm{e}$, competências concorrentes aos Estados, Distrito Federal e, novamente, à União ${ }^{15}$, permitindo, no primeiro caso, a delegação de competências aos $\operatorname{Estados}^{16} \mathrm{e}$, suplementarmente, pelos Municípios ${ }^{17}$.

No que tange ao meio ambiente, considerando o disposto no caput, do artigo 225, da $\mathrm{CRFB} / 88^{18}$, claro está o entendimento de que a preocupação com este bem tutelado deve permear todos os demais ramos do direito, devendo, portanto, na atuação legislativa do Estado, ser considerada imprescindível a análise das questões ambientais relacionadas.

Neste diapasão,

O Estado, nesse contexto, não está apenas "autorizado", mas sim, "obrigado" constitucionalmente (aqui por força dos seus deveres de proteção e promoção) a regulamentar a matéria ambiental nas mais diversas áreas (penal, civil, administrativa, processual, tributária, urbanística etc.) com o propósito maior de promover a proteção ambiental e elidir condutas e atividades lesivas ou potencialmente lesivas ao ambiente perpetradas tanto por particulares (pessoas físicas e jurídicas) quanto pelos próprios entes e agentes estatais ${ }^{19}$.

Desta forma, parece lógico que sendo uma obrigação do Estado, a atribuição de competência legislativa sobre questões ambientais deve estar vinculada a todos os entes federativos, ou seja, a regra é a da competência concorrente, obedecendo às orientações dos parágrafos do artigo 24, da CRFB/88, ressaltando, que a competência concorrente "enseja a possibilidade de iniciativa na área da legislação ambiental para os Estados e para o Distrito Federal, se a União se mantiver inerte"20.

Neste sentido, de forma comparativa, Machado, ao tratar da competência da União e dos Estados, trazendo ensinamento de Tomás-Ramon Fernandes, para exemplificar como a

\footnotetext{
${ }^{14}$ Artigo 22, da CRFB/88, anteriormente mencionado.

${ }^{15}$ Artigo 24, da CRFB/88, anteriormente mencionado.

${ }^{16}$ Artigo 22, Parágrafo único. Lei complementar poderá autorizar os Estados a legislar sobre questões específicas das matérias relacionadas neste artigo.

17 Art. 30. Compete aos Municípios: I - legislar sobre assuntos de interesse local;

${ }^{18}$ Art. 225. Todos têm direito ao meio ambiente ecologicamente equilibrado, bem de uso comum do povo e essencial à sadia qualidade de vida, impondo-se ao Poder Público e à coletividade o dever de defendê-lo e preservá-lo para as presentes e futuras gerações.

${ }^{19}$ SARLERT, Ingo Wolfgang; FENSTERSEIFER, Tiago. Direito constitucional ambiental: Constituição, direitos fundamentais e proteção do ambiente. $4^{a}$ Edição. Revista e atualizada. São Paulo: Revista dos Tribunais, 2014. p. 163

${ }^{20}$ MACHADO, Paulo Affonso Leme. Direito ambiental brasileiro. 25 ed. rev., ampl., e atual. São Paulo: Malheiros, 2017, p. 147.
} 
Espanha trata desta questão, sintetiza que o poder legislativo territorial (Comunidades Autônomas), em razão de especificidades regionais, acaba por gerar regras ou medidas mais rigorosas em relação à proteção do meio ambiente. Da mesma forma, para atender às peculiaridades próprias, a Constituição Federal, restou por permitir que os Estados exerçam a competência legislativa concorrentemente ${ }^{21}$.

Em relação ao conceito de norma geral, Paulo Affonso Leme Machado reforça que

A Constituição brasileira não conceitua norma geral. Resta à doutrina e à jurisprudência essa tarefa. A norma geral visa à aplicação da mesma regra em um determinado espaço territorial. A norma geral federal ambiental, ou em outra matéria de competência concorrente, não precisa necessariamente abranger todo o território brasileiro. Uma norma geral ambiental federal poderá dispor, por exemplo, sobre as áreas previstas no art. 225, $\S 4^{\circ}$ - Floresta Amazônica Brasileira, Serra do Mar, Mata Atlântica, Pantanal e Zona Costeira. A norma geral pode abranger somente um ecossistema, uma bacia hidrográfica ou somente uma espécie vegetal ou animal ${ }^{22}$.

E, continua,

A União está obrigada a inserir na norma geral o conteúdo dos acordos, tratados ou convenções internacionais já ratificados, depositados e promulgados pelo Brasil, como, evidentemente, guardar fidelidade à Constituição em vigor ${ }^{23}$.

Sobre a competência legislativa municipal prevista no artigo 30, incisos I e II, da $\mathrm{CRFB} / 88$, cabem aos municípios legislar sobre assuntos de interesse local e suplementar a legislação federal e a estadual no que couber. Embora tal dispositivo não faça menção expressa sobre a possibilidade de município legislar sobre matéria ambiental, tacitamente essa disposição está incluída no âmbito da competência legislativa concorrente, necessitando, para tanto, a leitura conjunta dos incisos VI, VII e VIII, do artigo 24, da CRFB/88 com os incisos I e II, do artigo 30, da CRFB/88, entendendo que não há qualquer razão para que a proteção do meio ambiente não fosse acobertada pelo conceito de interesse local ${ }^{24}$.

\footnotetext{
21 MACHADO, Paulo Affonso Leme. Direito ambiental brasileiro. 25 ed. rev., ampl., e atual. São Paulo: Malheiros, 2017. p. 145-147.

22 MACHADO, Paulo Affonso Leme. Direito ambiental brasileiro. 25 ed. rev., ampl., e atual. São Paulo: Malheiros, 2017, p. 145-147.

${ }^{23}$ MACHADO, Paulo Affonso Leme. Direito ambiental brasileiro. 25 ed. rev., ampl., e atual. São Paulo: Malheiros, 2017, p. 148.

${ }^{24}$ SARLERT, Ingo Wolfgang; FENSTERSEIFER, Tiago. Direito constitucional ambiental: Constituição, direitos fundamentais e proteção do ambiente. $4^{\text {a }}$ Edição. Revista e atualizada. São Paulo: Revista dos Tribunais, 2014.
} 


\subsection{Competência Executiva Ambiental}

As competências executivas ou materiais referem-se à possibilidade de atuação administrativa dos entes federativos, ou seja, executar, realizar, aplicar, fazer tornar realidade o que foi disposto em âmbito legislativo. As competências materiais ou executivas estão dispostas nos artigos 21 e 23, da CRFB/88, tecendo, no primeiro caso, a competência exclusiva da União e, no segundo, a competência comum entre União, Estados, Distrito Federal e Municípios.

Sobre o meio ambiente, apresentou-se nitidamente de que tal matéria necessita de atenção e envolvimento de todos os entes federativos. Assim, embora, o artigo 21, da CRFB/88 disponha indiretamente dessas questões, a atenção recai nos dispositivos elencados no artigo 23, da CRFB/88, dispondo sobre a responsabilização solidária dos entes envolvidos, cabendo a estes, por meio de suas atividades administrativas, "transpor a legislação ambiental para o «mundo da vida» assegurando a sua aplicação e efetividade" 25 .

Dentre as competências materiais mencionadas pelo artigo 23, da CRFB/88, atenta-se àquelas dispostas nos incisos III, IV, VI, VII, X e XI ${ }^{26}$.

Oportuno frisar que em razão da natureza das competências materiais comuns, visando ao atendimento de normas, na maioria das vezes, de caráter geral (Federal), reputa-se necessário que haja uma organização entre os entes federativos para que a concretização da vontade estampada na norma possa acontecer de forma eficaz. Neste sentido, o parágrafo único, do artigo 23, da CRFB/88, estabelece a necessidade de fixação, através de leis complementares, para a cooperação entre todos os entes federativos, buscando o equilíbrio do desenvolvimento e do bem-estar em âmbito nacional, contexto esse no qual se insere perfeitamente as questões ambientais, destacando-se que

\footnotetext{
${ }^{25}$ SARLERT, Ingo Wolfgang; FENSTERSEIFER, Tiago. Direito constitucional ambiental: Constituição, direitos fundamentais e proteção do ambiente. $4^{\mathrm{a}}$ Edição. Revista e atualizada. São Paulo: Revista dos Tribunais, 2014, p. 185 .

${ }^{26}$ Art. 23. (...) III - proteger os documentos, as obras e outros bens de valor histórico, artístico e cultural, os monumentos, as paisagens naturais notáveis e os sítios arqueológicos; IV - impedir a evasão, a destruição e a descaracterização de obras de arte e de outros bens de valor histórico, artístico ou cultural; VI - proteger o meio ambiente e combater a poluição em qualquer de suas formas; VII - preservar as florestas, a fauna e a flora; X combater as causas da pobreza e os fatores de marginalização, promovendo a integração social dos setores desfavorecidos; XI - registrar, acompanhar e fiscalizar as concessões de direitos de pesquisa e exploração de recursos hídricos e minerais em seus territórios.
} 
As leis complementares do parágrafo único do art. 23 da CRFB não têm por finalidade modificar o caput do próprio artigo, isto é, não podem pretender transformar competências, que são comuns, em competências privativas, únicas e especializadas. Se fossem esses os objetivos do parágrafo único, seria preciso uma transformação radical no texto do caput do art. $23^{27}$.

De acordo com Jair Schmitt e Fernando P. Scardua, "a descentralização é um processo pelo qual são transferidas responsabilidades de algumas funções do governo central para os governos locais, permitindo o equilíbrio do desenvolvimento e do bem-estar em âmbito nacional" 28 .

Como resultado da necessidade de se regulamentar a cooperação entre a União, Estados, Distrito Federal e Municípios, especialmente para tratar de questões ambientais dispostas nos incisos III, VI e VII, do artigo 23, da CRFB/88, foi promulgada a Lei Complementar $\mathrm{n}^{\circ}$. 140, de 08 de dezembro de 2011. Com isso, o ordenamento jurídico brasileiro, passou a contar com uma lei especifica sobre a organização das ações de cada um dos entes federativos, promovendo, consequentemente, uma descentralização, no caso específico, das políticas de meio ambiente.

Assim, ao verificar a formatação jurídica do sistema de distribuição de competências, como no caso das competências materiais ambientais, configurou-se a observância ao princípio ambiental da cooperação, sustentando-se que a "competência comum é aglutinadora e inclusiva, somando os intervenientes e não diminuindo ou tornando privativa a participação"29.

\section{LICENCIAMENTO AMBIENTAL DE ACORDO COM A POLÍTICA NACIONAL DO MEIO AMBIENTE E DA LEI COMPLEMENTAR Nº 140/2011}

A Lei Federal nº 6.938, de 31 de agosto de 1981, que instituiu a Política Nacional do Meio Ambiente (PNMA) é considerada uma importante base principiológica e de estruturação

\footnotetext{
${ }^{27}$ MACHADO, Paulo Affonso Leme. Direito ambiental brasileiro. 25 ed. rev., ampl., e atual. São Paulo: Malheiros, 2017, p. 188.

${ }^{28}$ SCHMITT, Jair; SCARDUA, Fernando P. A descentralização das competências ambientais e a fiscalização do desmatamento na Amazônia. Rev. Adm. Pública - Rio de Janeiro 49(5):1121-1142, set./out. 2015.

29 MACHADO, Paulo Affonso Leme. Direito ambiental brasileiro. 25 ed. rev., ampl., e atual. São Paulo: Malheiros, 2017, p. 189.
} 
do Sistema Nacional do Meio Ambiente (SISNAMA), inspirado no cooperativismo entre os entes federativos, objetivando a preservação, melhoria e recuperação da qualidade ambiental propícia à vida, visando assegurar no País, condições ao desenvolvimento socioeconômico, aos interesses da segurança nacional e à proteção da dignidade da vida humana ${ }^{30}$.

Ao estabelecer normas gerais de amplitude nacional, a Política Nacional do Meio Ambiente, assegura que cada ente federativo possa legislar para adaptá-la às suas realidades, sejam estas regionais ou locais. De outro lado, para a concretização ou realização da competência material, o Sistema Nacional do Meio Ambiente (SISNAMA), é composto em nível federal pelo Conselho de Governo, Conselho Nacional do Meio Ambiente, Ministério do Meio Ambiente, tendo como órgãos executores, o Instituto Brasileiro do Meio Ambiente e dos Recursos Renováveis (IBAMA) e o Instituto Chico Mendes de Conservação da Biodiversidade (Instituto Chico Mendes); em nível estadual, a competência fica reservada aos órgãos seccionais, criados por cada Estado, e, da mesma forma, com a competência municipal, a partir da criação de órgão locais ${ }^{31}$.

Sobre o licenciamento ambiental, a Lei $\mathrm{n}^{\circ}$. 6.938/1981 estabelece, no seu artigo $9^{\circ}$, inciso $\mathrm{IV}^{32}$, que o licenciamento e a revisão de atividades efetiva ou potencialmente poluidoras são instrumentos da Política Nacional do Meio Ambiente e, de acordo com o artigo $8^{\text {o33 }}$, da mesma lei, a competência para se estabelecer normas e critérios para o licenciamento de atividades efetivas ou potencialmente poluidoras, a ser concedido pelos Estados será do Conselho Nacional do Meio Ambiente (CONAMA), mediante proposta e supervisão do IBAMA.

\footnotetext{
${ }^{30}$ Art. $1^{\circ}$ - Esta lei, com fundamento nos incisos VI e VII do art. 23 e no art. 235 da Constituição, estabelece a Política Nacional do Meio Ambiente, seus fins e mecanismos de formulação e aplicação, constitui o Sistema Nacional do Meio Ambiente (Sisnama) e institui o Cadastro de Defesa Ambiental. (L. 6.938/1981)

${ }^{31}$ Art $6^{\circ}$ - Os órgãos e entidades da União, dos Estados, do Distrito Federal, dos Territórios e dos Municípios, bem como as fundações instituídas pelo Poder Público, responsáveis pela proteção e melhoria da qualidade ambiental, constituirão o Sistema Nacional do Meio Ambiente - SISNAMA, assim estruturado: VI - Órgãos Locais: os órgãos ou entidades municipais, responsáveis pelo controle e fiscalização dessas atividades, nas suas respectivas jurisdições. (L. 6.938/1981)

${ }^{32}$ Art $9^{\circ}$ - São instrumentos da Política Nacional do Meio Ambiente: IV - o licenciamento e a revisão de atividades efetiva ou potencialmente poluidoras. (L. 6.938/1981)

${ }^{33}$ Art. $8^{\circ}$ Compete ao CONAMA: I - estabelecer, mediante proposta do IBAMA, normas e critérios para o licenciamento de atividades efetiva ou potencialmente poluidoras, a ser concedido pelos Estados e supervisionado pelo IBAMA. (L. 6.938/1981)
} 
Importante destacar que na redação original do artigo $10^{34}$, da Lei 6.938/1981, sobre o órgão competente para o licenciamento ambiental, havia a menção expressa de que este seria o órgão estadual competente, integrante do SISNAMA, sem prejuízo de outras licenças exigíveis. Na sequência, por força da Lei 7.804/1989, a competência para o licenciamento passou a ser do órgão estadual competente, integrante do SISNAMA, e do IBAMA, em caráter supletivo, sem prejuízo de outras licenças exigíveis.

Desta forma, é possível vislumbrar, com certa nitidez, que a competência pelo licenciamento ambiental, de forma geral, era de caráter estadual, permanecendo desta maneira até a entrada em vigor da Lei Complementar 140/2011, cuja nova redação do artigo 10, da Política Nacional do Meio Ambiente, suprime a expressão "órgão estadual competente", fazendo referência apenas à necessidade de prévio licenciamento ambiental.

Ressalta-se, no que tange, segundo o artigo 17 - L, da Lei 6.938/1981, às ações de licenciamento, registro, autorizações, concessões e permissões relacionadas à fauna, à flora, e ao controle ambiental são da competência exclusiva dos órgãos integrantes do SISNAMA.

O conceito de licenciamento ambiental é trazido pelo artigo $2^{\circ}$, inciso I, da Lei Complementar $\mathrm{n}^{\circ} .140 / 2011$, como "sendo o procedimento administrativo destinado a licenciar atividades ou empreendimentos utilizadores de recursos ambientais, efetiva ou potencialmente poluidores ou capazes, sob qualquer forma, de causar degradação ambiental"35.

Também se encontra o conceito de licenciamento ambiental na Resolução CONAMA $\mathrm{n}^{\circ} .237$, de 19 de dezembro de 1997 e, antes de trazer o conceito à tela, necessário esclarecer que, como disposto anteriormente, cabe ao CONAMA o estabelecimento dos critérios de licenciamento ambiental e, a resolução posta aponta, dentre suas considerações, objetivos como dar execução a Política Nacional do Meio Ambiente, com a integração dos órgãos competentes do SISNAMA.

\footnotetext{
${ }^{34}$ Art. 10. A construção, instalação, ampliação e funcionamento de estabelecimentos e atividades utilizadores de recursos ambientais, efetiva ou potencialmente poluidores ou capazes, sob qualquer forma, de causar degradação ambiental dependerão de prévio licenciamento ambiental. § 1ํㅡㄹ Os pedidos de licenciamento, sua renovação e a respectiva concessão serão publicados no jornal oficial, bem como em periódico regional ou local de grande circulação, ou em meio eletrônico de comunicação mantido pelo órgão ambiental competente. (L. 6.938/1981).

${ }^{35}$ Art. $2^{\mathrm{o}}$ Para os fins desta Lei Complementar, consideram-se: I - licenciamento ambiental: o procedimento administrativo destinado a licenciar atividades ou empreendimentos utilizadores de recursos ambientais, efetiva ou potencialmente poluidores ou capazes, sob qualquer forma, de causar degradação ambiental; (LC 140/2011)
} 
Quanto ao conceito, a Resolução CONAMA n'. 237, de 19 de dezembro de 1997, define licenciamento ambiental como

procedimento administrativo pelo qual o órgão ambiental competente licencia a localização, instalação, ampliação e a operação de empreendimentos e atividades utilizadoras de recursos ambientais, consideradas efetiva ou potencialmente poluidoras ou daquelas que, sob qualquer forma, possam causar degradação ambiental, considerando as disposições legais e regulamentares e as normas técnicas aplicáveis ao caso ${ }^{36}$.

Na sequência é importante destacar que o artigo $1^{\circ}$, inciso II, Resolução CONAMA nº.

237, de 19 de dezembro de 1997, define licença ambiental como

ato administrativo pelo qual o órgão ambiental competente, estabelece as condições, restrições e medidas de controle ambiental que deverão ser obedecidas pelo empreendedor, pessoa física ou jurídica, para localizar, instalar, ampliar e operar empreendimentos ou atividades utilizadoras dos recursos ambientais consideradas efetiva ou potencialmente poluidoras ou aquelas que, sob qualquer forma, possam causar degradação ambiental ${ }^{37}$.

Paulo Renato Dallagnol, sobre a definição de licenciamento ambiental dispõe que este se trata de

uma forma de intervenção estatal na atividade privada, através do exercício do poder de polícia. É procedimento administrativo vinculado, através do qual são verificadas as condições para o desenvolvimento e a operação de empreendimentos passíveis de causarem danos ambientais ${ }^{38}$.

E, afirma que o licenciamento ambiental é uma

forma de exteriorização ou exercício do poder de polícia. Assim, como qualquer manifestação deste poder administrativo, é controle prévio à atividade privada; é ação que se antecipa à produção do dano ambiental ${ }^{39}$.

Sobre os órgãos competentes, a Resolução CONAMA nº. 237/97, estabelece no artigo $4^{\mathrm{o}}$, que as atividades e empreendimentos devem ser licenciadas pelo IBAMA (União), podendo delegar aos Estados o licenciamento de atividade com significativo impacto ambiental de âmbito regional, uniformizando, quando possível, as exigências; no artigo $5^{\circ}$, das atividades e

\footnotetext{
36 BRASIL. Conselho Nacional de Meio Ambiente. Resolução CONAMA nº. 237, de 19 de dezembro de 1997. Dispõe sobre a revisão e complementação dos procedimentos e critérios utilizados para o licenciamento ambiental. Ministério do Meio Ambiente: CONAMA, 1997. Diário Oficial da União. Brasília, 22 dez. 1997.

37 BRASIL. Conselho Nacional de Meio Ambiente. Resolução CONAMA nº. 237, de 19 de dezembro de 1997. Dispõe sobre a revisão e complementação dos procedimentos e critérios utilizados para o licenciamento ambiental. Ministério do Meio Ambiente: CONAMA, 1997. Diário Oficial da União. Brasília, 22 dez. 1997.

38 DALLAGNOL, Paulo Renato. O licenciamento ambiental municipal. Considerações acerca da repartição de competências entre os entes federativos. Revista Jus Navigandi, ISSN 1518-4862, Teresina, ano 11, n. 1264,17 dez. 2006. Disponível em: <https://jus.com.br/artigos/9292>.

${ }^{39}$ Idem
} 
empreendimentos a serem licenciados pelos Estados e Distrito Federal; e, no artigo $6^{\circ}$, ao órgão ambiental municipal, de empreendimentos e atividades de impacto ambiental local e daquelas que lhe forem delegadas pelo Estado por instrumento legal ou convênio.

Necessário destacar, de acordo com o artigo $7^{\circ}$, da Resolução CONAMA nº. 237/97, que os empreendimentos e atividades serão licenciados em um único nível de competência, ou seja, apenas Federal ou Estadual ou Municipal. Esta situação também foi recuperada pela Lei Complementar $n^{\circ} .140 / 2011$, em seu artigo $13^{40}$.

Em razão do estabelecimento de um único nível para o licenciamento ambiental e, para que seja de responsabilidade do município é necessário que tal competência seja delegada pelo Estado através de instrumento legal ou convênio.

Busca-se, portanto, na sequência, apresentar a contribuição da Lei Complementar $\mathrm{n}^{\circ}$. 140/2011, para a efetividade da referida delegação.

\section{ANÁliSE DA LEI COMPLEMENTAR No N $^{\circ}$ 140/2011 SOBRE A MUNICIPALIZAÇÃO DO LICENCIAMENTO AMBIENTAL}

Os objetivos fundamentais expressos no artigo $3^{\circ}$, da Lei Complementar $n^{\circ} .140 / 2011$, no exercício comum das competências da União, Estados, Distrito Federal e Municípios, se relacionam principalmente com a gestão descentralizada, democrática e eficiente; a erradicação da pobreza e a redução das desigualdades sociais e regionais, observados os princípios da dignidade da pessoa humana; a harmonização entre as políticas e ações administrativas, evitando-se, desta forma, a sobreposição de atuação entre os entes federativos; e, a uniformização da política ambiental para todo o país, respeitando as peculiaridades regionais e locais $^{41}$.

\footnotetext{
${ }^{40}$ Art. 13. Os empreendimentos e atividades são licenciados ou autorizados, ambientalmente, por um único ente federativo, em conformidade com as atribuições estabelecidas nos termos desta Lei Complementar. (LC 140/2011) ${ }^{41}$ Art. 3ํ Constituem objetivos fundamentais da União, dos Estados, do Distrito Federal e dos Municípios, no exercício da competência comum a que se refere esta Lei Complementar: I - proteger, defender e conservar o meio ambiente ecologicamente equilibrado, promovendo gestão descentralizada, democrática e eficiente; II - garantir o
} 
Diante disto, percebe-se a aderência do disposto na Lei Complementar nº. 140/2011 aos princípios constitucionais explícitos na Constituição Federal de 1988, especialmente, os artigos $1^{\circ}$, inciso III (dignidade da pessoa humana); $3^{\circ}$ inciso II (garantia do desenvolvimento sustentável) e, inciso III (erradicação da pobreza e da marginalização e redução das desigualdades sociais e regionais).

No mesmo diapasão, ressalta-se a necessidade de que haja cooperação entre os entes federativos visando a proteção do meio ambiente, de forma eficiente, levando o legislador a criar instrumentos para atingir tal finalidade, como consórcios públicos; convênios, acordos de cooperação técnica e outros instrumentos similares; delegação de atribuições e de execução de ações administrativas de um ente federativo a outro.

Sobre os aspectos de delegação, o artigo $5^{\circ}$, da Lei Complementar $n^{\circ}$. 140/2011, estabelece que

O ente federativo poderá delegar, mediante convênio, a execução de ações administrativas a ele atribuídas nesta Lei Complementar, desde que o ente destinatário da delegação disponha de órgão ambiental capacitado a executar as ações administrativas a serem delegadas e de conselho de meio ambiente ${ }^{42}$.

E, para esclarecer do que se trata um "órgão ambiental capacitado", o parágrafo único, do supracitado artigo, informa que se trata daquele que possui técnicos próprios ou em consórcio, devidamente habilitados e em número compatível com a demanda das ações administrativas a serem delegadas ${ }^{43}$.

Embora haja definição, ainda há margem extensa de interpretação em razão de conceitos vagos e que necessitam de uma complementação posterior, pois como determinar o número compatível de técnicos em relação a demanda, por exemplo.

\footnotetext{
equilíbrio do desenvolvimento socioeconômico com a proteção do meio ambiente, observando a dignidade da pessoa humana, a erradicação da pobreza e a redução das desigualdades sociais e regionais; III - harmonizar as políticas e ações administrativas para evitar a sobreposição de atuação entre os entes federativos, de forma a evitar conflitos de atribuições e garantir uma atuação administrativa eficiente; IV - garantir a uniformidade da política ambiental para todo o País, respeitadas as peculiaridades regionais e locais. (LC 140/2011)

${ }^{42}$ BRASIL. Lei Complementar $n^{\circ} .140$, de 8 de dezembro de 2011. Fixa normas, nos termos dos incisos III, VI e VII do caput e do parágrafo único do artigo 23 da Constituição Federal, para a cooperação entre a União, os Estados, o Distrito Federal e os Municípios nas ações administrativas decorrentes do exercício da competência comum relativas à proteção das paisagens naturais notáveis, à proteção do meio ambiente, ao combate à poluição em qualquer de suas formas e à preservação das florestas, da fauna e da flora; e altera a Lei n⿳o 6.938, de 31 de agosto de 1981. Diário Oficial da União, 12 dez. 2011.

${ }^{43}$ Idem
} 
Após a Lei Complementar no . 140/2011 definir as ações administrativas que são de competência da União e dos Estados, o artigo $9^{\circ}$, apresenta as ações administrativas dos Municípios, destacando-se aquelas inerentes ao licenciamento ambiental, dispostas nos incisos XIII, XIV e $\mathrm{XV}^{44}$.

Mesmo sendo atribuídas tais funções de licenciamento para o Município, a Lei Complementar 140/2011, dispõe que os demais entes federativos atuarão em caráter supletivo. Todavia, para o exercício do caráter supletivo do Estado em relação às atribuições do Município, o artigo 15, inciso II, menciona que este ocorrerá quando da inexistência do órgão ambiental capacitado ou conselho de meio ambiente na esfera local ${ }^{45}$.

Nos casos de atividades ou empreendimentos que causem ou possam causar impacto ambiental de âmbito local, conforme tipologia definida pelos respectivos Conselhos Estaduais de Meio Ambiente, considerados os critérios de porte, potencial poluidor e natureza da atividade ${ }^{46}$, o licenciamento ambiental por parte do município, somente será possível após a edição de decisão do Conselho Estadual de meio ambiente, todavia, enquanto não forem estabelecidas as referidas tipologias, os processos de licenciamento e autorização ambiental, continuarão a ser realizados em conformidade com os critérios até então estabelecidos pelas normativas vigentes ${ }^{47}$.

\footnotetext{
${ }^{44}$ Art. 9o São ações administrativas dos Municípios: XII - controlar a produção, a comercialização e o emprego de técnicas, métodos e substâncias que comportem risco para a vida, a qualidade de vida e o meio ambiente, na forma da lei; XIV - observadas as atribuições dos demais entes federativos previstas nesta Lei Complementar, promover o licenciamento ambiental das atividades ou empreendimentos: a) que causem ou possam causar impacto ambiental de âmbito local, conforme tipologia definida pelos respectivos Conselhos Estaduais de Meio Ambiente, considerados os critérios de porte, potencial poluidor e natureza da atividade; ou b) localizados em unidades de conservação instituídas pelo Município, exceto em Áreas de Proteção Ambiental (APAs); XV observadas as atribuições dos demais entes federativos previstas nesta Lei Complementar, aprovar: a) a supressão e o manejo de vegetação, de florestas e formações sucessoras em florestas públicas municipais e unidades de conservação instituídas pelo Município, exceto em Áreas de Proteção Ambiental (APAs); e b) a supressão e o manejo de vegetação, de florestas e formações sucessoras em empreendimentos licenciados ou autorizados, ambientalmente, pelo Município. (LC 140/2011)

${ }^{45}$ Art. 15. Os entes federativos devem atuar em caráter supletivo nas ações administrativas de licenciamento e na autorização ambiental, nas seguintes hipóteses: II - inexistindo órgão ambiental capacitado ou conselho de meio ambiente no Município, o Estado deve desempenhar as ações administrativas municipais até a sua criação. (LC $140 / 2011)$

${ }^{46}$ XIV - observadas as atribuições dos demais entes federativos previstas nesta Lei Complementar, promover o licenciamento ambiental das atividades ou empreendimentos: a) que causem ou possam causar impacto ambiental de âmbito local, conforme tipologia definida pelos respectivos Conselhos Estaduais de Meio Ambiente, considerados os critérios de porte, potencial poluidor e natureza da atividade; ou b) localizados em unidades de conservação instituídas pelo Município, exceto em Áreas de Proteção Ambiental (APAs). (LC 140/2011)

47 Art. 18. Esta Lei Complementar aplica-se apenas aos processos de licenciamento e autorização ambiental iniciados a partir de sua vigência. (LC 140/2011)
} 


\section{A VIABILIDADE DA MUNICIPALIZAÇÃO DO LICENCIAMENTO AMBIENTAL}

Preliminarmente, é possível entender que a municipalização do licenciamento ambiental traz vantagens para a proteção do meio ambiente, partindo da premissa que as atividades e empreendimentos são instalados ou desenvolvidos no município - na verdade, a vida acontece em âmbito local -, possibilitando uma melhor gestão e fiscalização de tais atividades ou empreendimentos. Sendo, portanto, o município

a instância mais adequada, na vastíssima maioria dos casos, para realizar o licenciamento ambiental, visto que todo impacto ambiental é, antes de tudo, local, atingindo outras instâncias, como a regional ou nacional, apenas em casos especiais ${ }^{48}$.

De forma simplista, imagina-se que o Estado, embora tendo competência para a realização do procedimento de licenciamento ambiental, é carente de estrutura e recursos financeiros e de pessoal para acompanhar e fiscalizar atividades e empreendimentos a serem instalados ou já em desenvolvimento em todos os municípios de seu território.

Baseado nesta inferência, a descentralização do licenciamento permite ação e fiscalização pontual, rápida e eficiente, possibilitando a celeridade administrativa do procedimento, diminuição de burocracia para os envolvidos, minimização de possíveis impactos, conhecimento das particularidades da região, entre outros.

Desta forma, a descentralização só será atingida quando as estruturas fiscalizadoras, também forem descentralizadas, em razão de "as atividades de fisscalização e controle permeiam organicamente a rede administrativa, tornando a função fiscalizadora mais próxima da fonte de execução da atividade correspondente e, portanto, da população"49.

Aparentemente, a municipalização está revestida de sensatez vez que tende a promover uma maior participação dos agentes, da comunidade local, da sociedade civil organizada, organismos de proteção ambiental, facilitando o acesso daqueles que buscam respaldo de

\footnotetext{
48 DALLAGNOL, Paulo Renato. O licenciamento ambiental municipal. Considerações acerca da repartição de competências entre os entes federativos. Revista Jus Navigandi, ISSN 1518-4862, Teresina, ano 11, n. 1264,17 dez. 2006. Disponível em: <https://jus.com.br/artigos/9292>.

49 Teixeira e Santana, citado em SCHMITT, Jair; SCARDUA, Fernando P. A descentralização das competências ambientais e a fiscalização do desmatamento na Amazônia. Rev. Adm. Pública - Rio de Janeiro 49(5):1121-1142, set./out. 2015.
} 
órgãos públicos para o desenvolvimento regular de suas atividades, bem como a fiscalização tende a ser mais eficiente em razão de funcionários públicos municipais assumirem tais atribuições de poder de polícia ambiental (considerando que se cada município tiver um único fiscal, alcançar-se-á quantitativo muito superior ao que os Estados membros mantem atualmente). Também, pressupõe-se uma tendência de os procedimentos de licenciamento serem menos custosos, em virtude de não dependerem mais de deslocamentos de funcionários e de empreendedores, ou seja, aliados ao aspecto de se vincular à uma única esfera, deve ser percebido uma otimização de tempo e recursos públicos, obedecendo-se à princípios de economicidade e eficiência.

De outro lado, algumas desvantagens podem ser apontadas, como o investimento na estruturação de equipes técnicas e de conselhos municipais, bem como dos próprios órgãos municipais que, de certa forma, podem sofrer com a influência ou interferência política e econômica de grupos de interesses.

Interessante apresentar a crítica de Paulo Affonso Leme Machado:

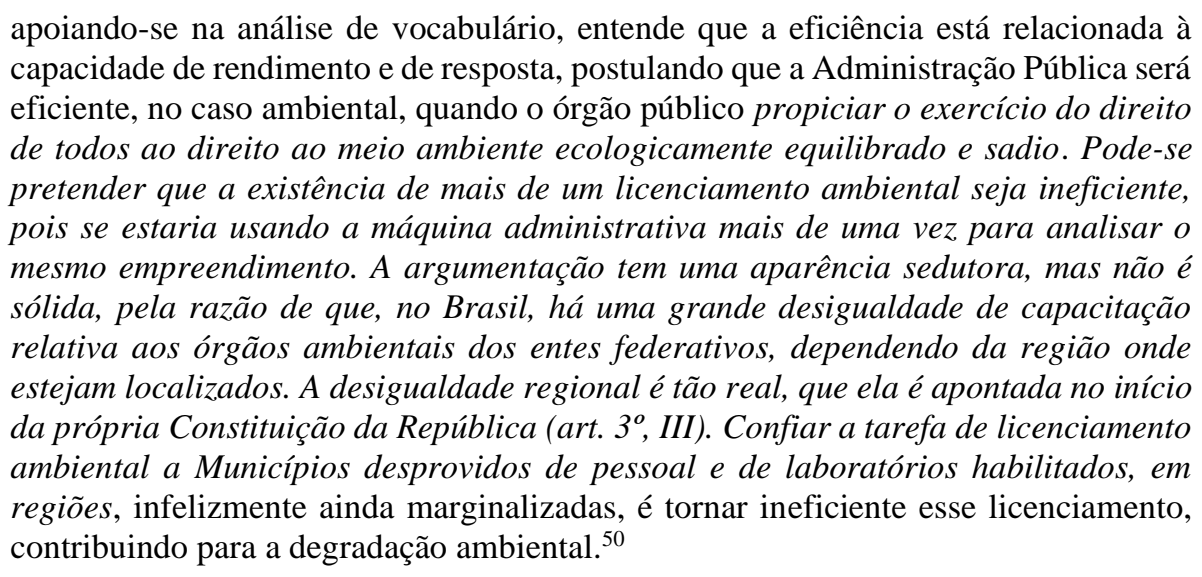

Em relação à equipe técnica, Gelze Serrat de Souza Campos Rodrigues, argumenta sobre a qualificação de seus membros, no sentido de que

apesar de o enfoque interdisciplinar ser enriquecedor e mesmo necessário à análise
dos processos de licenciamento, completando a percepção dos fenômenos e revelando
as suas interrelações, a especificidade da formação de cada profissional não deve ser
diluída ou reduzida, a ponto de se pensar que qualquer técnico possa analisar temas
de qualquer natureza, ou de que a flexibilidade e abertura a novos conhecimentos lhe

${ }^{50}$ MACHADO, Paulo Affonso Leme. Direito ambiental brasileiro. 25 ed. rev., ampl., e atual. São Paulo: Malheiros, 2017. p.332. 
promoverão a formação suficiente para assumir as competências profissionais de áreas de conhecimento diversas da sua ${ }^{51}$.

Essa é mais uma dificuldade que poderá ser enfrentada pelo Município, em especial, aqueles de pequeno porte, que sofrem com a falta de infraestrutura e de recursos financeiros grande parte dos municípios da atual realidade brasileira.

\section{CONCLUSÃo}

Ao tratar do sistema de distribuição de competências estabelecido na Constituição Federal de 1988 e, em especial, inerente ao tratamento da matéria ambiental, disposta na Lei Complementar $n^{\circ}$ 140/2011, bem como trazendo a contribuição de autores qualificados no assunto, percebe-se que um dos principais problemas relacionados ao conflito de competências está no modelo de federalismo adotado no Brasil desde a proclamação da República, no qual concentrava-se e, ainda, concentra-se uma gama relevante de atribuições na União, limitando, de certa forma, a atuação dos demais entes federativos, principalmente no que tange aos municípios.

A competência ambiental material caracteriza-se pela necessidade de cooperação entre todos os entes federativos visando a melhor eficiência na tutela do meio ambiente. Todavia, desde a promulgação da Constituição brasileira, em 1988, havia uma falha omissiva em relação ao que dispunha o parágrafo único, suprida apenas com a entrada em vigor da Lei Complementar $n^{\circ} 140 / 2011$.

Baseado no instrumento legislativo acima informado, abriu-se a possibilidade para que os municípios tivessem mais participação na atuação administrativa, exercendo seu poder de polícia em relação às atividades potencialmente poluidoras em seus territórios.

\footnotetext{
${ }^{51}$ RODRIGUES, Gelze Serrat de Souza Campos. A Análise interdisciplinar de processos de Licenciamento Ambiental no Estado de Minas Gerais conflitos entre velhos e novos paradigmas. Sociedade e Natureza, Uberlândia, 2010.
} 
Embora esta atuação municipal possa ser vista como uma importante contribuição para a tutela do meio ambiente, já que as atividades efetivamente acontecem em âmbito local, a permitir um processo de licenciamento de efetivo caráter preventivo, analisando todos os fatores correlacionados à tais atividades, em razão da cultura vinculada ao modelo de federalismo adotado no Brasil, os municípios, ainda carecem de estruturas adequadas para a concretização dos objetivos relacionados aos procedimentos administrativos na seara ambiental.

Desta forma, pelas exigências que são feitas aos municípios para que estes possam assumir o procedimento de licenciamento ambiental, principalmente, em ralação à composição de equipe técnica qualificada, em momento em que a maioria dos municípios passa por crises financeiras, a realidade de uma atuação eficiente parece estar um pouco distante, com riscos, inclusive, daqueles municípios que se responsabilizarem pelo licenciamento ambiental local, sem a efetiva estruturação, trazer resultados contrários aos interesses ambientais.

Isso não significa que este trabalho visa desestimular a atuação municipal na tutela do meio ambiente, pelo contrário, visa trazer elementos para reflexão e planejamento aos agentes públicos municipais, para que a decisão a ser tomada possa ser consciente e não oportunista, permitindo que o instrumento possa cumprir com as finalidades disposta nas políticas públicas ambientais, em especial, aquelas estipuladas na Lei $n^{\circ}$. 6.938/1981 - Política Nacional do Meio Ambiente.

\section{REFERÊNCIAS BIBLIOGRÁFICAS}

AMADO, Frederico Augusto Di Trindade. Direito ambiental esquematizado. $5^{\text {a }}$ Edição. São Paulo: Método, 2014.

BRASIL. Conselho Nacional de Meio Ambiente (1997). Resolução CONAMA $n^{o} .237$, de 19 de dezembro de 1997. Dispõe sobre a revisão e complementação dos procedimentos e critérios utilizados para o licenciamento ambiental. Ministério do Meio Ambiente: CONAMA, 1997. Diário Oficial da União. Brasília, 22 dez. 1997.

BRASIL. Constituição (1988). Constituição da República Federativa do Brasil. Brasília, DF, Senado, 1988. 
BRASIL. Lei Ordinária $n^{\circ}$. 6.938, de 31 de agosto de 1981. Dispõe sobre a Política Nacional do Meio Ambiente, seus fins e mecanismos de formulação e aplicação, e dá outras providências. Diário Oficial da União, Brasília, 2 set. 1981.

BRASIL. Lei Complementar $n^{o}$. 140, de 8 de dezembro de 2011. Fixa normas, nos termos dos incisos III, VI e VII do caput e do parágrafo único do artigo 23 da Constituição Federal, para a cooperação entre a União, os Estados, o Distrito Federal e os Municípios nas ações administrativas decorrentes do exercício da competência comum relativas à proteção das paisagens naturais notáveis, à proteção do meio ambiente, ao combate à poluição em qualquer de suas formas e à preservação das florestas, da fauna e da flora; e altera a Lei no $\mathbf{0} .938$, de 31 de agosto de 1981. Diário Oficial da União, 12 dez. 2011.

DALLAGNOL, Paulo Renato. O licenciamento ambiental municipal. Considerações acerca da repartição de competências entre os entes federativos. Revista Jus Navigandi, ISSN 15184862, Teresina, ano 11, n. 1264, 17 dez. 2006. Disponível em: $<$ https://jus.com.br/artigos/9292>.

MACHADO, Paulo Affonso Leme. Direito ambiental brasileiro. 25 ed. rev., ampl., e atual. São Paulo: Malheiros, 2017.

RODRIGUES, Gelze Serrat de Souza Campos. A Análise interdisciplinar de processos de Licenciamento Ambiental no Estado de Minas Gerais conflitos entre velhos e novos paradigmas. Sociedade e Natureza, Uberlândia, 2010.

SARLERT, Ingo Wolfgang; FENSTERSEIFER, Tiago. Direito constitucional ambiental: Constituição, direitos fundamentais e proteção do ambiente. $4^{\text {a }}$ Edição. Revista e atualizada. São Paulo: Revista dos Tribunais, 2014.

SCHMITT, Jair; SCARDUA, Fernando P. A descentralização das competências ambientais e a fiscalização do desmatamento na Amazônia. Rev. Adm. Pública - Rio de Janeiro 49(5):11211142, set./out. 2015.

SILVA, José Afonso da. Curso de direito constitucional positivo. 19 ed. São Paulo: Malheiros, 2001.

SILVA, Romeu Faria Thomé da. Manual de direito ambiental. $7^{\mathrm{a}}$ ed., rev., atual., e ampl. Salvador: JusPODIVM, 2017.

VERDÚ, Pablo Lucas. Curso de derecho político. v. 2. Madri: Tecnos, 1974.

Data de Submissão: 12/05/2020

Data de Aceite: 26/10/2020 